\title{
Institutional quality thresholds and the finance - growth nexus
}

\begin{abstract}
Using an innovative threshold estimation technique, this study examines whether the growth effect of financial development in countries with distinct levels of institutional development differs. The results demonstrate that there is a threshold effect in the finance-growth relationship. Specifically, we found that the impact of finance on growth is positive and significant only after a certain threshold level of institutional development has been attained. Until then, the effect of finance on growth is nonexistent. This finding suggests that the financial development-growth nexus is contingent on the level of institutional quality, thus supporting the idea that better finance (i.e., financial markets embedded within a sound institutional framework) is potent in delivering long-run economic development.
\end{abstract}

Keyword: Finance; Economic growth; Institutions; Threshold effect 